\title{
DISCONNECT BETWEEN DRIVER BEHAVIOR/PERFORMANCE STUDIES AND CRASH EXPERIENCE: LESSONS FROM THE STUDY OF YOUNG/INEXPERIENCED DRIVERS
}

\author{
Neil Lerner \\ Westat \\ Rockville, Maryland, USA \\ E-mail: lernern1@westat.com
}

\begin{abstract}
Summary: The quantitative measurement of driver behavior has been central to much of the systematic research underlying highway safety issues during the past forty years. It has contributed to the way in which we design roads, vehicles, training programs, signs and markings, and intelligent transportation systems. Yet the methods we use to conduct driver behavior experiments may result in a disconnect with the circumstances under which crash events occur. This is particularly evident in problems related to young, inexperienced drivers. This paper discusses some of the systematic biases that characterize the quantitative driver behavior research base regarding youthful drivers. Some broader implications for the general study of driver behavior and performance are then considered.
\end{abstract}

Empirical research on driver behavior has been central to the way in which we address many highway design and transportation safety issues. Driver performance is carefully measured during actual or simulated driving and the observations are applied to real-world safety countermeasures. The typical research paradigms reflect good scientific concern with controlled behavior, precise and repeatable measurement, and control over extraneous variables. This body of systematic research on driver behavior and performance has resulted in many important advances in highway safety. Yet the approach may also have promoted various systematic biases in the procedures, with the result that there may be a disconnect between the nature of a problem that motivated some research and the methods used to address the problem. The resulting findings may be incomplete or misleading.

Young, inexperienced drivers suffer especially high rates of crash involvement and experience difficulties in a variety of driving situations. Based on a recent review of the literature on young drivers (Lerner, Tornow, Freedman, Llaneras, Rabinovich, \& Steinberg, 2001), we noted that the limitations and biases of typical driver behavior research are particularly evident in the young/inexperienced driver area. Important driver behavior and performance problems evident from crash analysis, driver training experience, and even common anecdotal experience fail to emerge properly from typical youthful driver measurement efforts. Therefore considerations of this "disconnect" for the young driver area may be instructive for considering the problem for the broader highway safety domain.

\section{PASSENGER PRESENCE AND YOUNG DRIVER CRASHES}

The driving performance of young novice drivers is influenced by the presence of passengers. Table 1 presents a compilation of findings from several different U.S. and Canadian studies of 
young driver fatal crash involvement. The young driver data shown are for 16-year-olds, who represent the most extreme case (except for the crash involvement rates, which include 16-19 year olds). Similar, although somewhat reduced, effects would be evident for seventeen- and eighteen-year olds.

Table 1. Passenger Presence in Fatal Crashes for 16-Year-Old Drivers

\begin{tabular}{|c|c|c|}
\hline Fatal Crash Involvement Measure & 16 Year Olds & $\begin{array}{c}\text { Comparison } \\
\text { Group }\end{array}$ \\
\hline \multicolumn{3}{|l|}{ Passenger Presence (U.S. data) } \\
\hline \% drivers traveling with passengers, day ${ }^{1}$ & 62 & 37 \\
\hline$\%$ drivers traveling with passengers, night $^{1}$ & 70 & 35 \\
\hline$\%$ three or more occupants in vehicle ${ }^{2}$ & 33 & 18 \\
\hline \multicolumn{3}{|l|}{ Passenger Type $^{3}$ (U.S. data) } \\
\hline \% no passenger & 33 & 47 \\
\hline \% teenage passenger(s) only & 54 & 25 \\
\hline \% older passenger(s) only & 4 & 15 \\
\hline \% other passenger combinations & 10 & 12 \\
\hline \multicolumn{3}{|l|}{$\begin{array}{l}\text { Fatal Crash Involvement Rate (per } 100 \text { million driver- } \\
\mathrm{km})^{4} \text { (16-19 year olds; Ontario, Canada data) }\end{array}$} \\
\hline Male driver alone & 3.6 & 1.4 \\
\hline Male driver with passenger(s) & 9.0 & 2.1 \\
\hline Female driver alone & 2.0 & 1.3 \\
\hline Female driver with passenger(s) & 7.1 & 0.8 \\
\hline
\end{tabular}

${ }^{1}$ from Preusser, Ferguson, \& Williams (1998); comparison group is 30-59 years old

2 from Williams, Preusser, Ulmer, \& Weinstein (1995); comparison group is 25-49 years old

${ }^{3}$ from Ulmer, Williams, \& Preusser (1997); oldest comparison group was 19 years old

${ }^{4}$ from Doherty, Andrey, \& MacGregor (1998); comparison group is 25-59 years old

Some facts are striking from this table. A substantial majority of young driver fatal crashes occur with a passenger present. This is in contrast to more mature drivers (in this case, 30-59 year olds), where less than $40 \%$ of fatal crashes have a passenger present. One-third of the young driver fatal crashes had three or more vehicle occupants; this is almost double the frequency seen for more mature (25-49 year old) drivers. The enhanced risk due to passenger presence can be seen in terms of fatal crash involvement rates (per 100 million driver-km) with and without passengers. Without passengers, 16-19-year-old male drivers have a fatal crash involvement rate between two and three times that of more mature (25-59 year old) drivers. With passengers present, the involvement rate for 16-19-year-olds increases dramatically and is four to five times the rate of the mature drivers. A similar effect is seen for females. While passenger presence clearly has an effect, not all passengers may have the same influence on young drivers. More than half of the fatal crashes for 16 year olds had teenage passengers, and only teenage passengers, present. Only four percent had only non-teenage passengers. Since the exposure rate is not known (i.e., the proportion of driving done with teenage versus non-teenage passengers present) we cannot make definitive statements about the relative risk of driving with different types of passengers. However, since there are over 13 times more crashes with only teenage passengers than with only non-teenage passengers, it would appear very likely that agecohort passengers increase the crash risk for young drivers. Taking all the information in Table 1 together, it may be said that young driver fatal crash risk is substantially enhanced with age- 
peer passengers present and that the typical sixteen-year-old driver fatal crash involves the presence of one or more teenage passengers. This conclusion from crash data is consistent with the less formal observations of highway safety professionals, driver trainers, law enforcement, and common anecdotal experience.

Now let us turn to empirical driver behavior research that addresses young driver problems. A wide range of on-road studies have been done to assess young driver performance related to such factors as visual search, hazard recognition, steering control, curve negotiation, attention allocation, and so forth. In this paper it is not possible to discuss individual studies, but a good listing and review may be found in Mayhew and Simpson (1995). In virtually this entire literature, an experimenter accompanies the subject driver. As seen in Table 1, this passenger condition (non-teenage passenger) is representative of only about $4 \%$ of the novice driver fatal crashes. The literature also contains studies making use of driving simulators or part-task simulators. In virtually all of this literature, the subject "driver" is driving alone (although depending on the facility, an experimenter might be present). The "no passenger" condition accounts for only about a third of the fatal cases. Crash data and real-world experience teach us that young driver performance varies with passenger presence and that the most critical condition to deal with is the presence of age cohorts. Yet our studies of young driver performance do not systematically manipulate this variable and they manage to exclude the most critical condition entirely.

It is evident that our desire for strong methodology, ease of measurement, and control of variability may lead to an unrepresentative literature. It is difficult to criticize any single study on these grounds, but in the aggregate we have disconnected with the real-world safety problem to a certain degree. What, then, are we to make of the findings?

\section{OTHER YOUNG DRIVER CRASH RELATED FACTORS}

The passenger variable serves as a convenient example, but it is only one of various factors that present the general problem. If we directly compare knowledge of the young, novice driver safety problem on one hand with the nature of the driver performance measurement literature on the other, further contrasts emerge, such as the following.

Roadways. Young drivers do much less travel on freeways and major arterials than do mature drivers. A recent analysis of fatal crash data (Lerner et al., 2001) found that nearly half (46\%) of crashes for 30-39 year olds occurred on interstate highways, freeways, or principal arterials. In contrast only $30 \%$ of fatal crashes for 16 year olds occurred on such roads. Young drivers are over-represented in crashes on minor roads, including roads with narrow lanes, poor shoulders, and no median barrier. Yet typical roadways used for driver performance studies are major roadways.

In-vehicle distractors, attention allocation. Various events and activities compete for the driver's attention. Anecdotally it is believed that some of these activities (e.g., operating the entertainment system, interaction with passengers) are much more significant for young drivers. Research suggests that young drivers have poorer skill at allocating attention and also may be less cognizant of the hazards of distraction (Lerner et al., 2001). Yet driver performance studies generally eliminate potential distractions to the greatest extent possible. Thus studies of young 
driver steering, speed control, or risk perception all provide data in the context of distraction-free driving. How representative is the $85^{\text {th }}$ or $90^{\text {th }}$ percentile performance in such studies of comparable percentiles of real-world performance? If attention allocation is part of the normal driving process, and is a known problem for less experienced drivers, how informative is performance data based solely on the absence of all potential distractions?

Motivational factors. Driving behavior is influenced by driver motivations. Based on various sorts of qualitative sources (observational, focus groups, questionnaires, interviews), it is widely held that teenage driver behavior is often influenced by so-called “extra motives.” These are motivations unrelated to the primary driving task and include thrill seeking, competitiveness, aggression, sense of mastery, impressing peers, etc. These obviously can greatly influence realworld driving performance. The experimental situation limits these motivations as much as possible. Many young driver performance studies are concerned, directly or indirectly, with riskrelated behaviors: speed selection, risky acts, hazard recognition, sign use, and so forth. How representative are the findings if we constrain the motivational factors to only include "good" motivations?

Error recovery. Do the inflated crash rates of young drivers reflect a greater propensity to get into hazardous situations or a lesser ability to cope with hazardous situations once they arise? The literature indicates both sorts of problems exist, although the relative contribution of each is unknown. As drivers, we all recognize that we experience close calls or potential collisions frequently but we (hopefully) are involved in actual crashes rarely. Error recovery and crash avoidance maneuvering are key skills in preventing near-crashes from becoming crashes. Inexperienced drivers have less of this skill and are prone to over-steering and loss of braking control. Research on young driver behavior is focused on the commission of errors, with relatively little attention to how drivers cope with errors.

Risk management. Qualitative descriptions of driver behavior point out a striking contrast in the driving style of inexperienced and experienced drivers. Experienced drivers monitor and control the driving situation more effectively and manage potential risks so as to anticipate and control them before they emerge as serious. The "good" driver has a driving style that is described by terms such as "holistic," "predictive," and "context driven.” In contrast, the inexperienced driver tends to be more reactive, less situationally aware, and less of a manager of the continuously evolving traffic situation. This important contrast does not come through in typical young driver performance studies. We tend to analyze performance in terms of discrete responses (e.g., brake response, recognition distance) or global vehicle performance measures (e.g., lane position variance). These are easily measured and quantified sorts of events. But one characteristic of expert driving is its "smoothness" - that is, the absence of "events." The focus on discrete responses and specific errors fails to reflect another dimension of driving performance, albeit one more difficult to quantify.

\section{BROADER CONSIDERATION FOR DRIVER BEHAVIOR RESEARCH}

The preceding examples have illustrated how there is a disconnect between what we know about young driver problems and the way in which we go about conducting formal performance measurement studies of young drivers. Crash data, travel data, qualitative research, and expert experience provide a valuable sense of the nature of young driver problems. We tend not to view 
this real-world context when we design driver behavior/performance experiments and our methods are driven by other, also legitimate, methodological concerns. But as a result, we risk potentially misleading or incomplete findings. While these concerns are apparent for the inexperienced driver issue, they point to a need for similar concern in the more general study of driver behavior and performance. In typical driving studies we tend to eliminate or control many of the more critical crash-related aspects and then extrapolate from "normal” or "prototypical" driving performance to crash events. In many highway applications we tend to use upper percentile data (e.g., the $85^{\text {th }}$ or $90^{\text {th }}$ percentile driver) for design purposes. Yet we exclude from our procedures those conditions that in the real world are likely to produce the upper percentile responses. There is an absence of distractions, passengers, competing motivations, even a need to plan and navigate a route. There may be qualitative changes in driving style, as well as quantitative changes in driver response, under a broader range of typical driving conditions. Consider the fact that driver inattention and distraction have been estimated to be contributing factors to somewhere between $25 \%$ to $50 \%$ of crashes. Yet unless an experiment is explicitly directed at the issue of distraction, we try to study driver performance in a distraction-free environment.

Explicitly or implicitly, the field has used a model of crash-critical performance as an extension of the normal distribution of prototypical performance aspects (the "tail of the curve") rather than as "rare event" driven ("lapses," "incidents," "planning failures”). We tend to ask questions in the form of "how does driver X respond to factor Y," and then measure response Z. We tend not to ask the question in the form "under the challenges of the normal range of driving conditions, how does factor $\mathrm{Y}$ influence the manner in which driver $\mathrm{X}$ manages his risk environment?” We will need to remain sensitive to the bounds of normal driving as the driving task and environment continue to evolve. With the advent of intelligent transportation systems and vehicle telematics, experts see the driving task as evolving into one of information management as much as of mechanical control. Aspects of vehicle control and monitoring are becoming shared with intelligent vehicle systems, such as adaptive cruise control and crash avoidance warning devices. Navigation, information, and entertainment functions will be available while driving. In this emerging driving world, how should the "normal" driving task be captured in driver performance research? We may need to re-think some of our research paradigms and may need to take greater advantage of technologies that support naturalistic driving research and driving simulation.

In pointing out the disconnect between crash experience and driver performance experiments, the intent is not to criticize any individual study of young drivers or drivers in general. Many of these studies are excellent and stand perfectly well on their own, and their methodological choices may be reasonable for the particular experiment. The criticism is really with what happens when we consider the literature in aggregate. The world in which research participants drive does not always match up well with the real world in which crashes occur, and the performance measures we make may not always capture the essence of crash causation. Future empirical research on driver performance might benefit if the research community gives greater consideration to this concern. 


\section{REFERENCES}

Doherty, S., Andrey, J., \& MacGregor, C. (1998). The situational risks of young drivers: The influence of passengers, time of day, and day of week on crash rates. Accident Analysis and Prevention, 30(1), 45-52.

Lerner, N., Tornow, C., Freedman, M., Llaneras, R., Rabinovich, B., \& Steinberg, G. (2001). Preliminary Investigation of Highway Design Countermeasures to Aid Drivers with Limited Experience: Final Report. Final report under Contract DTFH61-98-C-00063. Washington, DC: Federal Highway Administration,.

Mayhew, D., \& Simpson, H. (1995). The Role of Driving Experience: Implications for the Training and Licensing of New Drivers. Report No. ISBN 1-895792-01-0. Toronto, Ontario: Insurance Bureau of Canada.

Preusser, D., Ferguson, S., \& Williams, A. (1998). The effect of teenage passengers on the fatal crash risk of teenage drivers. Accident Analysis and Prevention, 30(2), 217-222.

Ulmer, R., Williams, A., \& Preusser, D. (1997). Crash involvements of 16-year-old drivers. Journal of Safety Research, 28(2), 97-103.

Williams, A., Preusser, D., Ulmer, R., \& Weinstein, H. (1995). Characteristics of fatal crashes of 16-year-old drivers. Journal of Public Health Policy, 16(3), 347-360. 